\title{
LA EVOLUCIÓN DEL DERECHO AL SUICIDIO ASISTIDO Y LA EUTANASIA EN LA JURISPRUDENCIA CONSTITUCIONAL COLOMBIANA: OTRA MUESTRA DE UNA DISCUTIBLE UTILIZACIÓN DE LA DIGNIDAD
}

\section{The evolution of assisted-suicide and euthanasia rights in Colombia's Constitutional Court's case-law: Once again, a questionable use of dignity}

\author{
CARMEN TOMÁS-VALIENTE LANUZA \\ Universidad de las Islas Baleares \\ carmen.tomas-valiente@vib.es
}

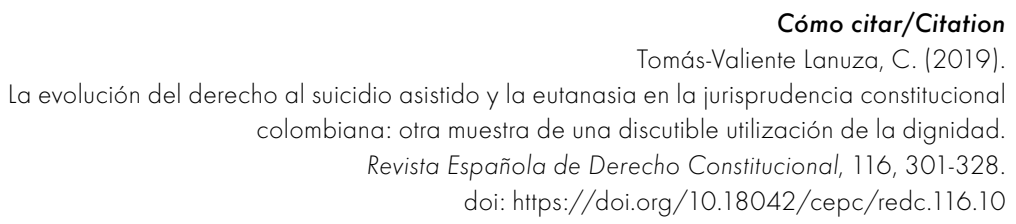

Resumen

Dos recientes sentencias de 2017 de la Corte Constitucional de Colombia han supuesto una ampliación de los sujetos titulares del derecho a la eutanasia, declarado como fundamental por la Corte en 1997: de su configuración inicial como un derecho de libertad de los enfermos terminales capaces de decidir, anclado en el necesario respeto a su dignidad/autonomía moral, se ha pasado a atribuirlo también — sobre la base de una interpretación de la dignidad centrada en la evitación del sufrimiento y no tanto en la idea de autonomía - a niños, nińas y adolescentes terminales que atraviesen graves padecimientos (lo que supone que en caso de ser totalmente incapaces el derecho sería ejercitado por sus padres). El presente trabajo analiza el fondo de esta jurisprudencia y destaca (además de la necesidad de separar el debate sobre la «buena muerte» en relación con pacientes competentes y los que no lo son) lo que se considera una discutible utilización del lábil concepto de dignidad como parámetro de enjuiciamiento de la constitucionalidad de las normas. 


\title{
Palabras clave
}

Eutanasia; suicidio asistido; dignidad; autonomía; derecho a morir.

\begin{abstract}
Two recent 2017 decisions of Colombia's Constitutional Court have widened the scope of the right to euthanasia, first declared by the Court in its 1997 ruling. From its initial configuration as a fundamental liberty right, based upon the dignity/ autonomy of terminally ill, competent patients, it has come to be attributed (on the basis of an idea of dignity centered on the avoidance of suffering and not so much on the autonomy notions of the first decision) to terminally ill and seriously suffering girls, boys and teenagers (which means that in cases of their complete lack of competence the right is exercised by their parents). This paper analyses the core of this jurisprudence and highlights (in addition to the need to distinguish between competent and non-competent patients when discussing "good death" matters) what is considered a questionable use of the labile concept of dignity as a parameter for judging the constitutionality of laws.
\end{abstract}

\section{Keywords}

Euthanasia, assisted-suicide, dignity, autonomy, right to die. 
I. INTRODUCCIÓN. II. LA FUNDAMENTACIÓN DEL DERECHO SOBRE LA DIGNIDAD (ENTENDIDA COMO AUTONOMÍA MORAL Y DERECHO A NO SUFRIR): LA SENTENCIA C-239/1997. III. LA SENTENCIA T-970-14: REGULACIÓN DEL DERECHO TRAS LA PASIVIDAD DEL LEGISLADOR. IV. LAS SENTENCIAS T-544/17 Y T-721/17: LA PREVALENCIA DEL DERECHO A NO SUFRIR. EL CONSENTIMIENTO SUSTITUTO: 1. El cambio de enfoque. 2. Nuevos desencuentros con el Ministerio de Salud. La Resolución 825 de 2018. V. ALGUNAS REFLEXIONES. BibIOGRAFIA.

\section{INTRODUCCIÓN}

En un contexto como el actual, en el que especialmente en temas de derechos fundamentales asistimos a lo que se ha denominado una cierta "globalización judicial» —entendida, sin perjuicio de las peculiaridades de cada ordenamiento jurídico, como una intensificación del intercambio de ideas y experiencias entre jurisdicciones constitucionales de distintos países, que a menudo desemboca en influencias recíprocas-, parece interesante contribuir a dar a conocer las últimas decisiones de la Corte Constitucional de Colombia relativas al «derecho fundamental a la muerte digna», que pivotan sobre nociones centrales (autonomía individual, dignidad) comunes a los ordenamientos constitucionales de las sociedades occidentales ${ }^{1}$.

1 Sobre los rasgos de esa «globalización judicial», interesante Slaughter (2005: 65 y ss.). Aunque no vaya a ser objeto de este trabajo, no puede dejar de mencionarse la sentencia Carter v Canadá, de 6 de febrero de 2015 (2015 SCC 5) del Tribunal Supremo del Canadá, segunda jurisdicción constitucional, después de la colombiana, en declarar como fundamental el derecho de los enfermos a recibir ayuda activa para morir (sea en la forma de suicidio asistido o eutanasia) y en anular la prohibición penal de estas conductas, lo que ha resultado finalmente en la aprobación de la Ley de 17 de junio de 2016 reguladora del derecho. Un completo análisis y crítica puede encontrarse en Rey Martínez (2015), que llama la atención sobre la influencia que la sentencia está llamada a desplegar en el debate, o en Gimbel García (2016).

En estas páginas adoptamos la terminología absolutamente asentada en la actualidad en la literatura filosófico-jurídica, que distingue entre suicidio asistido o médicamente asistido (el enfermo es quien se produce la muerte con ayuda externa) y eutanasia (el adelantamiento de la muerte, inicialmente típico de homicidio, es causado por el médico). 
El interés intrínseco de esta jurisprudencia, que ha dado lugar en el ordenamiento jurídico colombiano a una situación sin precedentes en el panorama del Derecho comparado, reside, al menos, en dos razones: en primer lugar, en que permite constatar, según creo, algunas dificultades inherentes al hecho de que el reconocimiento del derecho a solicitar ayuda externa para morir sea fruto del cuestionamiento de la constitucionalidad de las normas que la incriminan y no de una decisión del legislador democrático (dificultades en el caso colombiano evidenciadas, aunque no solo, en los desencuentros muy notables entre la propia Corte Constitucional, el legislador y últimamente también el Ministerio de Salud); y en segundo lugar, en que en esta jurisprudencia de la Corte colombiana puede apreciarse una utilización a mi juicio muy poco clara del siempre lábil y maleable concepto de dignidad, que desde su inicial conexión preferente con la idea de autonomía individual (base en la sentencia de 1997 de la declaración de inaplicabilidad de la prohibición penal del homicidio piadoso solicitado por el enfermo) ha pasado después a concebirse sobre todo en clave de una especie de "derecho a no sufrir», lo que ha conducido al Alto Tribunal, en dos sentencias de 2017, a ordenar al legislador (y en su defecto, al Ministerio de Salud) incluir en la regulación de la eutanasia los supuestos de niños, niñas y adolescentes en situación terminal que padecen sufrimientos muy severos (donde los padres, en caso de menores no maduros, ejercerían un mal llamado "consentimiento sustituto») ${ }^{2}$. Analizaremos críticamente estos pronunciamientos con el propósito de darlos a conocer pero también para, a partir de ellos, realizar una serie de reflexiones de carácter general que quizás puedan resultar pertinentes en el momento actual, en el que la regulación de la eutanasia parece cada vez más próxima ${ }^{3}$.

Para no llamar a engaño al lector, y para evitar que mi postura crítica con esta jurisprudencia genere una impresión equivocada sobre la que con carácter

2 La multiplicidad de formas que en los textos constitucionales (por lo general, posteriores a la Segunda Guerra Mundial) adopta la consagración normativa de la dignidad es sobradamente conocida (derecho fundamental per se, valor superior, principio, etc.); al margen del diverso grado de prescriptibilidad que ello pueda comportar, todas ellas comparten, sin embargo, una enorme indefinición en cuanto al contenido de aquello que se consagra, inherente al propio concepto de dignidad — por todos, Chueca Rodríguez (2015) — . Dicha vaguedad resulta clave en la construcción jurisprudencial que analizaremos, lo que nos permitirá realizar una serie de consideraciones que exceden el caso colombiano.

3 En la pasada legislatura se inició la tramitación parlamentaria de una Proposición de la ley orgánica de regulación de la eutanasia $(B O C D$, XII Legislatura, Serie B, Núm. 270-2, 2 de julio de 2018) que parece plausiblemente augurar que será reiniciada. 
general sostengo respecto a la eutanasia y el suicidio asistido, me parece conveniente adelantar ya algunas de las conclusiones de estas páginas, así como sintetizar ciertos presupuestos de partida desarrollados en otros trabajos. Mi punto de vista es decididamente favorable a la derogación de las normas vigentes que criminalizan estas conductas y a que el ordenamiento garantice un derecho de los ciudadanos a recibir ayuda para adelantar su muerte cuando libremente así lo decidan en contextos de grave enfermedad o discapacidad e intensos sufrimientos (Tomás-Valiente Lanuza, 1999: 113-124 y 149-153); y aunque existen argumentos nada despreciables en favor de la declaración de inconstitucionalidad de dicha incriminación (por coartar la autonomía individual en un aspecto tan fundamental e íntimo de nuestra existencia) ${ }^{4}$, entiendo preferible que la decisión proceda del legislador, dotado de legitimación democrática directa y mucho mejor situado que la jurisdicción constitucional, contramayoritaria por definición, para ponderar a través de la deliberación democrática las ventajas e inconvenientes de la desincriminación 5 . En la jurisprudencia que vamos a analizar se ponen de manifiesto, creo —y más allá de que el punto de llegada respecto a la eutanasia solicitada nos parezca en sí mismo deseable- algunos de los inconvenientes de que el derecho sea declarado ex novo por un tribunal o corte constitucional, que se agudizan cuando para fundamentarlo se recurre a la dignidad como canon autónomo de constitucionalidad.

\section{LA FUNDAMENTACIÓN DEL DERECHO SOBRE LA DIGNIDAD (ENTENDIDA COMO AUTONOMÍA MORAL Y DERECHO A NO SUFRIR): LA SENTENCIA C-239/1997}

La comprensión del conjunto de la jurisprudencia constitucional colombiana sobre este tema requiere remontarse a la Sentencia seminal C-239/97, en

4 Al margen de encontrarse estrechamente ligada a las peculiaridades constitucionales estadounidenses, un puesto de privilegio en esta línea sigue ocupando la construcción de Dworkin (1998).

5 Tomás-Valiente Lanuza (1999: 295 y ss., 379 y ss.). Una línea similar puede encontrarse en Ruiz Miguel (2010: 37-40), con una excepción importante para el caso de las situaciones trágicas - parálisis totales o similares - en las que el enfermo no puede suicidarse por sí mismo, a las que entiende que debe darse cobijo constitucional a través del amparo sin que ello signifique la inconstitucionalidad directa de la incriminación del resto de los casos; más brevemente, y también desde una perspectiva favorable a la legalización, Chueca Rodríguez (2009: 122). Una clarificadora visión de conjunto ofrece Du Bois-Pedain (2007: 86-87). Sobre la objeción democrática o contramayoriaria, por todos, Ferreres Comella (2007: 43 y ss.). 
la que la Corte declaró parcialmente inaplicable el art. 326 del Código Penal entonces vigente (el Decreto 100 de 1980), que tipificaba el que el propio Código denominaba homicidio por piedad («el que matare a otro por piedad, para poner fin a intensos sufrimientos provenientes de lesión corporal o enfermedad grave o incurable, incurrirá en prisión de seis meses a tres años»). El fallo resultaba sorprendente, ya de entrada, a la vista de la fundamentación del recurso (la "demanda de inexiquibilidad» en la terminología procesal colombiana). Y es que en este no se sostenía la inconstitucionalidad del precepto por constituir un exceso ilegítimo de intervención penal limitadora de la autonomía del ciudadano enfermo, sino precisamente por todo lo contrario: lo que se pretendía era la anulación del art. 326 por motivos diametralmente opuestos, esto es, por considerarlo incurso en un defecto de protección penal de la vida, al prever unas penas excesivamente benignas que a juicio del actor comportaban una especie de legalización encubierta del homicidio de enfermos y discapacitados $^{6}$. Estas alegaciones fueron descartadas por el Tribunal en los primeros fundamentos jurídicos de la sentencia, al considerar que la atenuación de la pena disciplinada por el precepto respecto del homicidio básico en atención a los motivos pietísticos entroncaba con el principio de proporcionalidad de las penas de modo perfectamente compatible con el texto constitucional'; pero una vez sentado este extremo, el Tribunal pasó, por su propia iniciativa, a valorar de manera más completa el precepto a la luz de la Constitución de 1991, y más en concreto a la luz del principio de autonomía —esto es, en lo que se refiere a su aplicación a homicidios piadosos solicitados por el enfermo-. Es así como lo que entró en la Corte colombiana como una

6 Sobre los deberes positivos estatales de protección penal me permito remitir a Tomás-Valiente Lanuza (2016). Es por cierto del todo previsible que, en caso de ser finalmente aprobada en nuestro país, la ley orgánica de regulación de la eutanasia termine siendo recurrida ante el Tribunal Constitucional, recurso que probablemente se estructuraría en torno a la idea de la vulneración de los deberes estatales positivos de protección (penal) de la vida — prolijamente desarrollados, mucho más que por nuestro TC, en la jurisprudencia del TEDH- Aunque no sea este el objeto de estas líneas, interesa mencionar que nada en la copiosa jurisprudencia del Tribunal de Estrasburgo sobre los deberes de protección de la vida (como tampoco en la del TC) permite apuntalar la idea de que la despenalización vulnere per se el art. 2 del CEDH (ni el art. $15 \mathrm{CE}$ ). Siempre que se articule un sistema adecuado de garantías que evite prácticas incorrectas o abusivas (como por otra parte sucede desde hace años en el ámbito del rechazo del paciente a un tratamiento médico), no hay tacha alguna de inconstitucionalidad -y por cierto, la proposición, de 2018 era extremadamente garantista en este sentido-.

7 Sentencia C-239/1997, II, B. 
demanda contra el art. 326 CP basada en la infraprotección penal de la vida desembocó en una estimación de su inconstitucionalidad por el motivo justamente contrario: por constituir un exceso de represión penal incompatible con el principio de autonomía personal y con la dignidad del enfermo.

Dejemos en cualquier caso al margen esta peculiaridad de la sentencia (que a mi entender colocó al Estado en una posición de inferioridad procesal, puesto que al introducir la Corte una perspectiva totalmente diferente a la del recurso no se dio a aquel la oportunidad de defender la constitucionalidad del precepto en esos nuevos términos) ${ }^{8}$ y centrémonos ahora en lo que la vertebra, esto es, las apelaciones repetidas a las nociones centrales de dignidad y autonomía. Interesa constatar que la base inicial de la construcción de la sentencia es en primera instancia el art. 1 de la Constitución de 1991 y su mención de la dignidad humana como fundamento del Estado colombiano. Adoptado este punto de partida, la Corte parece identificar la dignidad en primer lugar con uno de los varios sentidos que en el lenguaje filosófico-jurídico suelen atribuirse al concepto9: la dignidad como reconocimiento de la autonomía moral. Se insiste así en la idea de que la atención a la dignidad implica el respeto al «libre desarrollo de la personalidad» del individuo, «su autonomía e identidad» o su «inextirpable singularidad», y se clarifica especialmente que «la Constitución se inspira en la consideración de la persona como un sujeto moral, capaz de asumir en forma responsable y autónoma las decisiones sobre los asuntos que en primer término a él incumben ${ }^{10}$. Respetar la dignidad del individuo implica, pues, respeto a sus decisiones más básicas, entre las que se encuentra la de cómo morir.

Junto a ello, la sentencia alude extensamente a la idea del sufrimiento, y también la liga a la misma noción de dignidad: constantemente se refiere a la idea de «morir de forma digna», que identifica con la de «morir sin sufrimiento» (así, por ejemplo, cuando recalca que «frente a los enfermos

8 La Corte asigna a la prohibición penal una ratio religiosa - lo que como es obvio facilita enormemente su posterior argumentación - sin dar al Estado la posibilidad de defender ninguna otra fundamentación constitucionalmente admisible. Sobre esta cuestión del argumento religioso véase Aguirre et al. (2015). El reduccionsimo de la sentencia contrasta en este sentido con la canadiense Carter, que hace gala de mucha mayor solidez en su análisis de las razones que podrían justificar constitucionalmente la criminalización [aunque finalmente las descarte y declare la inconstitucionalidad de las prohibiciones penales, revirtiendo con ello la doctrina previamente sentada en Rodríguez v British Columbia, (1993) 3 S.C.R. 519].

9 De los que me he ocupado con cierta extensión en Tomás-Valiente Lanuza (2014a).

10 Sentencia C-239/1997, II.C.1 
terminales que experimentan intensos sufrimientos, este deber estatal [de protección de la vida] cede frente al consentimiento informado del paciente que desea morir en forma digna», o cuando se refiere a la persona que sufre, ya en todo caso en un proceso terminal, «dolores insoportables, incompatibles con su idea de dignidad») $)^{11}$. Y todo ello le conduce a afirmar, finalmente, que "por consiguiente, si un enfermo terminal que se encuentra en las condiciones objetivas que plantea el artículo 326 del Código Penal considera que su vida debe concluir, porque la juzga incompatible con su dignidad, puede proceder en consecuencia, en ejercicio de su libertad, sin que el Estado esté habilitado para oponerse a su designio, ni impedir, a través de la prohibición o de la sanción, que un tercero le ayude a hacer uso de su opción $»^{12}$. Por todo ello, la Corte exhorta al Congreso para que en el tiempo más breve posible regule la cuestión conforme a los principios sentados en la sentencia ${ }^{13}$.

Este derecho a la muerte digna, declarado por la sentencia como verdadero derecho fundamental, se asienta, por tanto, sobre dos pilares, autonomía individual y evitación del sufrimiento insoportable (anudado a su vez a la condición de enfermo terminal), que según la sentencia han de concurrir conjuntamente. La concreta articulación de estos factores con la dignidad no termina sin embargo de ser del todo aclarada por la Corte; pues si bien la argumentación se asienta, como ya se ha visto, sobre la dignidad en tanto fuente de la autonomía moral del individuo (que sería uno de sus contenidos básicos), en otros, en cambio, parece conferirse a la autonomía un espacio propio e identificar la dignidad más con la idea de derecho a no sufrir de modo insoportable. Con todo, la omnipresencia de la noción de dignidad en toda la argumentación de la sentencia permite entender que ambos factores (autonomía y derecho a no sufrir) son considerados por la Corte como emanaciones o contenidos básicos de aquella, y sobre ellos se construye el derecho fundamental.

Precisamente la interrelación de lo que podríamos llamar estas dos lógicas - la de la autonomía y la del sufrimiento insoportable - en el seno de la dignidad devendrá en punto clave de la jurisprudencia de la Corte sobre este tema: pues si bien en la sentencia de 1997 se insiste en el peso irrenunciable de la primera ${ }^{14}$, las de 2017 , en cambio, otorgarán un mayor protagonismo a la

11 Sentencia C-239/1997, II.C.3. La evitación del sufrimiento se liga también al «principio de solidaridad» del art. 95 de la Constitución colombiana, entendido como deber de socorrer a quien se encuentra en una situación de necesidad.

12 Ibid.

13 Sentencia C-239/1997, III.

14 En su bosquejo de lo que debería ser la futura regulación del derecho, insistió la Corte en que el primero de ellos debería ser una «verificación rigurosa [...] de la 
segunda, lo que ha desembocado en la configuración de un panorama, como veremos, considerablemente distinto al inicialmente dibujado veinte años atrás. De esta evolución nos ocuparemos más adelante (infra, III). En este momento interesa tan solo realizar alguna observación adicional sobre el tratamiento de este binomio autonomía-sufrimiento (de interrelación consustancialmente problemática) en esta primera sentencia.

Resulta inmediatamente evidente que cualquier reconocimiento (sea en la jurisprudencia constitucional o por la legalidad ordinaria) del derecho a recibir ayuda externa para adelantar la propia muerte ha de enfrentarse a la cuestión de la delimitación material de las situaciones (de enfermedad, de sufrimiento) que a la postre determinan a quién se atribuye su titularidad. Cuanta mayor relevancia jurídica (sobre todo si es considerada derecho fundamental) se atribuya a la autonomía individual y al deber de respetarla, más aguda es la paradoja y mayor el esfuerzo argumental necesario para justificar una delimitación restrictiva de su ámbito de operatividad como la acogida en la sentencia C-239/97 al acotarlo a los enfermos terminales.

La resolución constituye, ciertamente, un buen ejemplo de esta contradicción y de un modo nada satisfactorio de abordarla. En efecto: al argumentar la fuerza de la autonomía moral del individuo como base del derecho, la Corte insiste en una comprensión acentuadamente antipaternalista del papel del Estado - al que parece concederse poco margen para limitar la libertad de los ciudadanos en aras de su supuesto bienestar o protección-, que de hecho ya había venido impregnando su jurisprudencia sobre temas más o menos conexos con el que nos ocupa ${ }^{15}$. Una buena síntesis de esta actitud

situación real del paciente, de la enfermedad que padece, de la madurez de su juicio y de la voluntad inequivoca de morir» (sentencia C-239-97, II, D; la cursiva es nuestra). Previamente había insistido (II. C.3) en que «el consentimiento del sujeto pasivo debe ser libre, manifestado inequívocamente por una persona con capacidad de comprender la situación en que se encuentra. Es decir, el consentimiento implica que la persona posee información seria y fiable acerca de su enfermedad y de las opciones terapéuticas y su pronóstico, y cuenta con la capacidad intelectual suficiente para tomar la decisión» (cursiva nuestra).

15 Son conocidas las sentencias de la Corte colombiana sobre rechazos de tratamiento, consumo de drogas u obligación de portar casco o cinturón de seguridad (en la que realiza un test de proporcionalidad que modera el antipaternalismo de partida). Una útil panorámica sobre el activismo de la Corte en estos y otros ámbitos ofrece su exmagistrado Cepda-Espinosa (2004: 578-585). Contextualiza la Sentencia C-23997 en el conjunto de la jurisprudencia de la Corte y también en otros aspectos interesantes de la sociedad colombiana, como el acceso a los cuidados paliativos Díaz Amado (2017). 
— precisamente al resumir su propia jurisprudencia al respecto- puede encontrarse en la posterior sentencia T-970/14 (que enseguida examinaremos):

En el caso de la muerte digna, la Sala de Revisión, al igual que la Sala Plena en la Sentencia C-239 de 1997, considera que su principal propósito es permitir que la vida no consista en la subsistencia vital de una persona sino que vaya mucho más allá. Esos aspectos adicionales son propios de un sujeto dotado de dignidad que como agente moral, puede llevar a cabo su proyecto de vida. Cuando ello no sucede, las personas no viven con dignidad. Mucho más si padece de una enfermedad que le provoca intenso sufrimiento al paciente. En estos casos, ¿quién si no es la propia persona la que debe decidir cuál debería ser el futuro de su vida? ¿Por qué obligar a alguien a vivir, en contra de su voluntad, si las personas como sujetos derechos pueden disponer ellos mismos de su propia vida?

Lejos de ser preguntas abiertas, los interrogantes planteados muestran la estrecha relación que tiene el derecho a la muerte digna con la dignidad humana. En criterio de esta Sala, morir dignamente involucra aspectos que garantizan que luego de un ejercicio sensato e informado de toma de decisiones, la persona pueda optar por dejar de vivir una vida con sufrimientos y dolores intensos. Le permite alejarse de tratamientos tortuosos que en vez de causar mejoras en su salud, lo único que hacen es atentar contra la dignidad de los pacientes. Cada persona sabe qué es lo mejor para cada uno y el Estado no debe adoptar posiciones paternalistas que interfieran desproporcionadamente en lo que cada cual considera indigno ${ }^{16}$.

Ahora bien: si se parte de modo tan intenso de la premisa de la autonomía individual para decidir sobre la propia vida, no termina de justificarse por qué se impone el parámetro objetivo que asigna la titularidad del derecho tan solo a los enfermos terminales ${ }^{17}$. La noción de sufrimiento juega así un doble papel de fundamentación y límite: por una parte sustenta el derecho a la muerte digna, pero a la vez acota el alcance más amplio al que su reconocimiento en tanto derecho de autonomía podría conducir. De alguna forma,

16 Sentencia T-970/14, II, 5.3 (el pasaje ilustra a la vez la integración del concepto de dignidad con el doble componente de autonomía y derecho a no sufrir).

17 Esta objeción se ha formulado tanto desde la discrepancia con el fondo de la sentencia (así, en el voto particular del magistrado Hernández Galindo), como desde la perspectiva favorable al reconocimiento del derecho, que sin embargo se entiende excesivamente limitado por la Corte —Lozano Villegas (2001: 100); García Pereáñez (2016: 210)—. Muestra sus reservas Michlowski (2009: 204-207, 210). 
pareciera que la Corte parte de la premisa de que el único sufrimiento realmente intenso (tanto como para devenir a su juicio incompatible con la dignidad) es el que sobreviene en fase terminal, cosa que es empíricamente incorrecta - no puede ponerse en duda la intensidad del padecimiento físico y psíquico de una persona aquejada de ELA, o en situación de absoluta dependencia derivada de lesiones medulares, ictus, etc.más, de que la no inclusión de este tipo de pacientes bajo el manto del derecho contradice claramente el antipaternalismo adoptado como punto de partida, al constreñir - aquí de un modo en el fondo más intenso que en situaciones de muerte muy próxima - el respeto al plan o proyecto de vida del individuo que tan decididamente proclama como base de la dignidad. La sentencia de 1997 no intenta justificar esta limitación, que parece difícilmente argumentable desde sus propias premisas; solo el tiempo dirá si — como se ha producido ya en otros contextos que enseguida examinaremos - la propia Corte terminará ampliando la titularidad del derecho fundamental a raíz de la interposición (perfectamente imaginable) de una demanda por algún enfermo de estas características ${ }^{18}$.

\section{LA SENTENCIA T-970-14: REGULACIÓN DEL DERECHO TRAS LA PASIVIDAD DEL LEGISLADOR}

El exhorto final dirigido por la Corte al legislador colombiano en 1997 no hizo mella en este último; aunque se presentaron hasta cuatro proyectos en el Congreso, lo cierto es que en el año 2000 se aprobó incluso una reforma del Código Penal que expresamente seguía considerando delictivas conductas que de acuerdo con la sentencia se encontraban amparadas por el derecho a la muerte digna ${ }^{19}$. Es en este contexto en el que, diecisiete años después, la Corte emite una nueva sentencia, a raíz del recurso de una ciudadana enferma

18 Bien es cierto que la atribución contenida en la sentencia puede interpretarse como de mínimos: respecto de los pacientes terminales hablaríamos necesariamente de un derecho fundamental pero nada impediría al legislador, en un ulterior desarrollo normativo, ampliarla a este otro tipo de pacientes o a otros grupos de casos como los que a día de hoy ya se encuentran incluidos en la legislación de Países Bajos y Bélgica (véase infra IV). Pero si el legislador — como hasta el momento sucede- no recoge estos supuestos, parece previsible que antes o después termine presentándose alguna reclamación ante la Corte.

19 Arts. 106 y 107 del nuevo Código Penal, aprobado por Ley 599 de 2000, de 24 de julio. Se plantea aquí la interesante cuestión (más compleja de lo que inicialmente 
terminal de cáncer a la que en la vía judicial previa se había denegado, con el argumento del vacío normativo existente, la ayuda a morir que reiteradamente solicitaba. Pues bien: por más que considere que tras su declaración vinculante en la sentencia de 1997 el derecho es directamente aplicable (en virtud sobre todo de su directa conexión con la dignidad) aun sin contar con ulterior desarrollo normativo, la Corte reconoce que de facto la falta de regulación dificulta (como demuestra el caso sometido a su conocimiento) el ejercicio efectivo del derecho por los ciudadanos ${ }^{20}$. Entiende por tanto imprescindible que se proceda de inmediato a disciplinar el procedimiento concreto de ejercicio del derecho, que ella misma diseńa en la sentencia (ya con un grado de concreción notable), y que, según ordena, habrá de ser plasmado por el Ministerio de Salud en un plazo perentorio de treinta días ${ }^{21}$. Nace así — tras la denegación mediante auto de la ampliación del plazo solicitada por el ministerio ${ }^{22}$ - la Resolución del Ministerio de Salud 1216 de 2015, que a día de hoy constituye (complementada por la Resolución 825 de 2018, a la que luego se hará referencia) la regulación en vigor sobre la eutanasia y el suicidio asistido en Colombia ${ }^{23}$.

Sin duda, lo anómalo de todo este iter suscita numerosos interrogantes sobre el eterno problema del equilibrio de poderes entre legislador y jurisdicción constitucional, pues ciertamente en esta sentencia se intensifica la arrogación por la Corte de un papel normador que en puridad debería corresponder al primero (y en el que la intervención del Ejecutivo debiera por cierto ser solo secundaria); pero críticas al margen (unas críticas que en realidad habrían de retrotraerse ya a la sentencia del 97), lo cierto es que la sentencia de 2014 es una consecuencia lógica de la emitida diecisiete años atrás, que se orienta a lograr la efectividad de un derecho declarado como fundamental. Lo que ya no lo es, aunque en la argumentación de la Corte pueda parecerlo, es la mención a una cuestión que en esta sentencia de 2014 pasa casi inadvertida pero que posteriormente —a la luz de dos posteriores sentencias de 2017— se ha

podría parecer) de hasta qué punto puede el legislador reiterar preceptos previamente anulados por el TC. Sobre ello, con un criterio flexible, Viver Pi-Sunyer (2013).

Sentencia T-970-14, II, 5.3, o 7.1.4.

Sentencia T-970-14, II, 7.2.

Auto 098 de 27 de mayo de 2015.

De 20 de abril, disponible en https://bit.ly/1FkuLC9. A los efectos de este trabajo no interesa detenerse en las particularidades del procedimiento diseñado por la resolución. Baste apuntar que los centros hospitalarios están obligados a disponer de un así llamado "Comité científico-interdisciplinario para el derecho a morir con dignidad», competente para recibir las peticiones de ayuda para morir y para valorar los requisitos de estado terminal y firmeza de la voluntad del paciente. 
revelado capital: me refiero al consentimiento que la sentencia denomina «por sustitución", cuya mención inicial y posterior desarrollo en la jurisprudencia de la Corte pasamos a tratar a continuación.

\section{LAS SENTENCIAS T-544/17 Y T-721/17: LA PREVALENCIA DEL DERECHO A NO SUFRIR. EL CONSENTIMIENTO SUSTITUTO}

\section{EL CAMBIO DE ENFOQUE}

Tras dos sentencias también del mismo año pero de importancia menor (una de las cuales confirma que la denegación de la eutanasia a un anciano de noventa años con depresión severa no vulnera el derecho fundamental ${ }^{24}$, y otra que sí declara dicha vulneración al apreciarse una burocratización excesiva que impidió la prestación de la eutanasia a una enferma terminal ${ }^{25}$ ), el 25 de agosto de 2017 la Corte emite la Sentencia T-544 (relativa a un adolescente en situación terminal e incapaz desde su nacimiento), en la que el análisis se sitúa de pleno, por primera vez, en la cuestión del consentimiento por sustitución; tan solo unos meses después, el 12 de diciembre (cuatro sentencias en un mismo ańo dan cuenta del peso específico del derecho a la muerte digna en el orden constitucional colombiano y en la jurisprudencia de la Corte), se emite la Sentencia T-721/17, también sobre una adolescente con una profunda minusvalía psíquica desde muy niña y en estado vegetativo permanente ${ }^{26}$.

El tema, como se decía, se mencionó ya, pero solo brevemente, en la Sentencia T-970/14. En efecto, en su diseño de la regulación que el ministerio habría de aprobar, señaló la Corte (por cierto sin aportar fundamentación ulterior alguna) que

el consentimiento también puede ser sustituto. Esta manera de manifestar el consentimiento ocurre cuando la persona que sufre de una enfermedad terminal, se encuentra en imposibilidad fáctica para manifestar su consentimiento. En esos casos y en aras de no prolongar su sufrimiento, la familia, podrá sustituir su consentimiento. En esos eventos, se llevará a cabo el mismo procedimiento

24 Sentencia T-322/17, de 12 de mayo.

25 Sentencia T-423/17, de 4 de julio, en la que la Corte ordena al ministerio crear mecanismos de agilización del procedimiento.

26 En esta sentencia se añade, además, el problema de determinar si se encontraba o no en estado terminal en el momento en que sus padres plantean la petición de que se adelante su fallecimiento. 
establecido en el párrafo anterior, pero el comité interdisciplinario deberá ser más estricto en el cumplimiento de los requisitos ${ }^{27}$.

Así dejaba las cosas la Corte en la sentencia citada. El ministerio, por su parte, no recogió el guante: si bien al regular las competencias de los comités el art.7.8 de la Resolución 1216 de 2015 les asignaba la de «verificar, en el caso del consentimiento sustituto, si existe alguna circunstancia que llegue a viciar la validez y eficacia del mismo», lo cierto es que en la regulación concreta del procedimiento de solicitud y práctica de la eutanasia la intervención de las personas legitimadas para dar el consentimiento por sustitución se previó como instrumento de activación del procedimiento solo si la persona incapaz hubiera dejado previamente constancia expresa de su voluntad en un documento de voluntades anticipadas (art. 15) —en la línea de las regulaciones despenalizadoras vigentes en Países Bajos, Bélgica y Luxemburgo, que expresamente contemplan esta posibilidad-; en relación con incapaces, solo estos supuestos se consideran, en suma, un ejercicio expreso (aunque previo) de autonomía. Casos como los analizados en las sentencias T-544/17 y T-721/17, relativos a adolescentes con profundas minusvalías psíquicas que nunca habían manifestado voluntad alguna ni hubieran podido hacerlo, no se encontraban comprendidos por la regulación administrativa.

Es cierto, y conviene hacerlo notar, que el objeto de ambas sentencias no se limita exclusivamente al problema de si a estos enfermos les debió ser reconocido el derecho a recibir eutanasia activa. Especialmente en la sentencia T-721/17 la Corte insiste en que este último constituye tan solo uno de los diversos contenidos del derecho fundamental a morir dignamente, que además del anterior incorporaría también el derecho de todo enfermo a decidir sobre el propio tratamiento y a rechazar medidas terapéuticas, y los derechos a la limitación del esfuerzo terapéutico inútil y a recibir los cuidados paliativos necesarios para aliviar el sufrimiento ${ }^{28}$. Proyectada sobre el supuesto enjuiciado, esta configuración amplia del derecho a la muerte digna permitió a la Corte apreciar su vulneración por las entidades prestadoras del servicio sanitario ya de entrada por el hecho de no haber procurado a estos pacientes el tratamiento paliativo necesario (sobre todo la T-721/17) ${ }^{29}$. Pero con todo y con eso, la Corte, en especial la sentencia T-544/17, se adentra también en el derecho rela-

Sentencia T-970/14, II, 7.2.9.

28 Sentencia T-721/17, V.6.1.8.

29 En el caso de la Sentencia T-544/17, más que en el aspecto de la falta de cuidados paliativos (aunque también se mencionan), el no haber procurado un tratamiento 
tivo a recibir ayuda activa para adelantar el fallecimiento (pues en ambos supuestos el detonante del proceso que culmina ante la Corte es la presentación por los padres de una solicitud de que se activara el procedimiento regulado en la resolución ministerial de 2015), y en la espinosísima cuestión de a quién se atribuye su titularidad — que la sentencia plantea, dada la edad del paciente, en relación a los «niños, niñas y adolescentes»"

Pues bien: es en este punto clave en el que el juego de equilibrios entre las dos bases del derecho declarado en la sentencia de 1997 (autonomía de la voluntad y derecho a no sufrir) se ve trastocado en favor del peso decisivo del segundo. La lógica de la Corte es tan sencilla como (a mi juicio) tramposa: se explica que los fundamentos de su jurisprudencia anterior «se han centrado en destacar la especial relevancia que cobra la dignidad humana cuando un enfermo en fase terminal padece intensos dolores y sufrimientos, y cómo el sometimiento a estas circunstancias constituye un trato inhumano», y a partir de aquí se insiste en que "considerar que solo son titulares del derecho los mayores de edad [...] llevaría a admitir tratos crueles e inhumanos de los menores de edad, y la afectación de su dignidad ${ }^{31}$. El derecho al adelantamiento de la muerte (y la previa noción de dignidad que lo sustenta) pasa a centrarse así en el derecho de los enfermos en situación terminal a que se ponga fin a su sufrimiento (sean o no mayores de edad), y no tanto en su facultad de exigir el respeto a su voluntad cuando se deciden en este sentido. No faltan referencias al Derecho comparado: tras un muy breve repaso de la regulación vigente en Bélgica y en los Países Bajos (con una expresa alusión al conocido como "protocolo de Groningen», que en este último país opera de facto como regulación que autoriza el adelantamiento de la muerte de recién nacidos que padecen sufrimientos insoportables sin perspectivas de mejora), la Corte no duda en calificar el tema concreto de la eutanasia en recién nacidos como no "pacífico». Pero, añade, "con independencia de esas discusiones, la dignidad humana como principio fundante del ordenamiento jurídico colombiano y por tanto del Estado, reconocida como principio constitucional general y derecho fundamental autónomo obliga a reconocer la titularidad del derecho a la muerte digna de los niños, niñas y adolescentes», titulares cuya edad ciertamente introduce «diferencias y particularidades [...] principalmente en los aspectos relacionados con el consentimiento y la manifestación de la

adecuado a la dramática situación del adolescente se considera vulnerador, con carácter más general, del derecho a la salud (II.44-45).

30 Designados a lo largo de todo el texto con el acrónimo NNA.

31 Sentencia T-544, II.37. Igualmente en II.50. 
voluntad», pero que en todo caso han de ver regulado y garantizado su derecho «y así evitar que sean sometidos a tratos crueles e inhumanos y obligados a soportar graves sufrimientos $»^{32}$.

En este desplazamiento de la argumentación hacia lo que aquí denominamos «el factor sufrimiento» la Corte insiste en que nada en su jurisprudencia anterior permite negar a los menores la titularidad del derecho, y que «el hecho de que los pronunciamientos de la Corte Constitucional se hayan emitido en el marco de casos en los que estaban involucradas personas mayores de 18 años es una contingencia, que no comporta una limitación del alcance del derecho fundamental a la muerte digna fundada en la edad». Ha de recordarse, sin embargo, que aun sin excluirlos expresamente (a los menores ni a incapaces en general), la sentencia seminal de 1997 sí había insistido repetidamente en la necesidad de comprobar, como presupuesto del derecho, la madurez de juicio del enfermo y su capacidad de entender su situación ${ }^{33}$; una delimitación que podría abarcar a los menores maduros, pero a contrario excluía claramente a los menores sin capacidad de juicio y a los adultos incapaces (al menos, aunque nada se decía en la sentencia sobre las voluntades anticipadas, a los que pudiendo haberlo hecho no hubieran dejado constancia previa alguna de su voluntad, y claramente a los incapaces absolutos que nunca han gozado de capacidad de juicio); fue solo en la sentencia de 2014 donde, sin mayor fundamentación ni ulterior especificación de los supuestos allí comprendidos, se introdujo casi inadvertidamente, como hemos visto, la noción del «consentimiento sustituto». En contra de lo que la Corte pretende hacer pasar como una concatenación lógica indiscutible, el peso esencial atribuido a la autonomía individual en la fundamentación del derecho sí comportaba — no podía ser de otro modo - una delimitación de su titularidad en la sentencia de 1997; solo una completa reinterpretación (por no decir tergiversación) de su argumentación puede pretender presentar la atribución del derecho a sujetos incapaces como una continuación necesaria de lo sostenido en la sentencia fundacional.

Pues bien, una vez ampliada de esta forma la titularidad del derecho, la Corte considera, como ya hizo en la sentencia de 2014 con carácter general, que la falta de una regulación específica para los enfermos terminales niños, niñas y adolescentes les impide el ejercicio del derecho fundamental, por lo que ordena al Ministerio de Salud que establezca un protocolo al respecto (en un plazo de cuatro meses), a lo que se ańade la reiteración del exhorto al legislador para que en un plazo máximo de dos años promulgue una regulación

32 Todo ello en sentencia T-544/17, II.38.

33 Véanse las contundentes afirmaciones reproducidas supra nota 14. 
del derecho a la muerte digna tanto para mayores como menores de edad ${ }^{34}$. En lo que a menores se refiere, la propia sentencia ofrece ya ciertas indicaciones, en las que llama la atención el que, en la línea ya citada de insistir en la continuidad con la Sentencia C-239/97, se siga partiendo del paradigma del consentimiento (a través de la figura del "consentimiento sustituto») también en los casos de menores no maduros o totalmente incapaces en los que la solicitud es formulada por sus padres. Merece la pena reproducir estos párrafos:

La previsión del consentimiento informado establecido en la sentencia C-239 de 1997 en el marco del ejercicio del derecho a la muerte digna debe evaluarse, de forma particular, de cara a los titulares del derecho. En efecto, aunque por regla general los NNA expresan el consentimiento a través de sus representantes es necesario que en estos casos se consulte, de forma prevalente, su voluntad siempre que el desarrollo psicológico, emocional y cognitivo del NNA lo permitan.

En este punto es indispensable la experticia de los profesionales que pueden evaluar el nivel de desarrollo cognitivo de los NNA, que pueden determinar la mejor manera de darles información y que deben manejar la concurrencia con el consentimiento de ambos padres, que siempre será obligatorio. En los casos en los que la representación legal sea ejercida por otros individuos o que los NNA se encuentren bajo la protección del Estado, la valoración del consentimiento sustituto deberá ser estricta.

Asimismo, y de forma subsidiaria deberá analizarse el consentimiento sustituto por imposibilidad fáctica para manifestar la voluntad derivada de una condición de salud o del desarrollo cognitivo del NNA. En estos eventos, los padres, personas o entidades que se encuentren legalmente a cargo pueden sustituir el consentimiento y se llevará a cabo el mismo procedimiento, pero el comité interdisciplinario deberá ser más riguroso en el cumplimiento de los requisitos y en el análisis de la situación.

En síntesis, el consentimiento informado del paciente como presupuesto para el ejercicio del derecho a la muerte digna de acuerdo con la sentencia C-239 de 1997 debe ser expresado directamente por los NNA cuando su desarrollo cognitivo, psicológico y emocional lo permitan. En los casos en los que el NNA se encuentra en imposibilidad fáctica para manifestar su voluntad se evaluará el consentimiento sustituto de forma estricta ${ }^{35}$.

34 Sentencia 544/17, II.55.

35 Sentencia 544/17, II.54. Además de por la indefinición inherente al concepto de dignidad, el salto lógico de la sentencia al atribuir el derecho a los nińos, nińas y adolescentes puede haberse visto favorecido por el hecho de que el derecho al adelantamiento de la muerte de enfermos capaces para decidir solo se había reconocido (y así se mantiene) 
De todo lo anterior se desprende, pues (en una síntesis que en este momento pretendemos puramente objetiva del núcleo central de la sentencia), que según la Corte el Estado colombiano se encuentra constitucionalmente obligado a regular, como expresión del mismo derecho fundamental a la muerte digna sentado por la Sentencia C-239/97, la práctica de la eutanasia activa - siempre que concurra una situación de terminalidad y sufrimiento insoportable - a menores psicológica y cognitivamente maduros para consentir (cosa que también deben hacer ambos progenitores o quienes ejerzan su representación legal) y a menores que no puedan expresar voluntad alguna, caso este último en el que la petición de la práctica de la eutanasia, que será evaluada de forma especialmente estricta, será presentada por sus progenitores o representantes legales. Se reconozca o no, y aunque no se enuncie expresamente - formalmente se trata de una sentencia de las denominadas de tutela, y no de constitucionalidad como la de 1997-, la sentencia viene de facto a ampliar el objeto de la declaración de «inexequibilidad» dictada veinte ańos atrás, que de afectar inicialmente al homicidio solicitado por enfermos terminales mentalmente capaces pasa a comprender ahora el de nińos, niñas y adolescentes enfermos terminales solicitado por ellos (cuando se les reconozca madurez suficiente) o por sus representantes legales (cuando no la tengan).

\section{NUEVOS DESENCUENTROS CON EL MINISTERIO DE SALUD. LA RESOLUCIÓN 825 DE 2018}

En contra de lo que podría pensarse, los desencuentros entre la Corte Constitucional y el Gobierno colombiano no pueden darse ni mucho menos por concluidos con las sentencias de 2017 y la resolución ministerial subsiguiente. Y ello porque si bien el Ministerio de Salud, en cumplimiento de lo ordenado, emite en efecto su Resolución 825, por medio de la cual se reglamenta el procedimiento para hacer efectivo el derecho a morir con dignidad de niños, niñas y adolescentes ${ }^{36}$, lo cierto es, sin embargo, que la disposición

para situaciones de terminalidad, lo que trasladado al ámbito de los incapaces podría dar la impresión de que se reconoce únicamente para situaciones extremas muy acotadas. El concepto de terminalidad habitualmente manejado en medicina, sin embargo, es el de un pronóstico de muerte próxima en un plazo inferior a unos seis meses, y desde luego no coincide con el de encontrarse ya en un proceso próximo a la agonía (que es el contexto en el que comúnmente se admite la sedación).

36 De 9 de marzo de 2018, disponible en https://bit.ly/2Fpf1qE. La resolución abarca también aspectos en los que no entraremos aquí, como la necesidad de garantizar a 
contradice de modo palmario lo dispuesto por el Alto Tribunal. La discrepancia es clara: frente a la — según acaba de explicarse- tajante atribución del derecho por la Corte a todos los niños, niñas y adolescentes, y su determinación de que en los casos de «imposibilidad fáctica para manifestar la voluntad derivada de una condición de salud o del desarrollo cognitivo del NNA» entre en juego consentimiento sustituto - descripción de la situación con la que nos parece claro que la Corte pretende referirse tanto a nińos muy pequeños como a nińos y adolescentes con discapacidad cognitiva, como era precisamente el caso de las sentencias de 2017-, la resolución opta por una delimitación de la posibilidad de solicitar el procedimiento que excluye expresamente (art. 3) a "recién nacidos y neonatos», "primera infancia» y al "grupo poblacional de los 6 a los 12 años» (salvo, en este último caso, que el niño o niña posea un grado excepcional de desarrollo neurocognitivo y psicológico), además de a niños, nińas y adolescentes que presenten "estados alterados de conciencia», «discapacidades intelectuales» $\mathrm{o}$ "trastornos psiquiátricos diagnosticados que alteren la competencia para entender, razonar y emitir un juicio reflexivo». Que en estos supuestos queda vedada a los titulares de la patria potestad (u otros representantes legales) la activación del procedimiento a través del consentimiento sustituto se evidencia en el art. 11, que opera con un concepto totalmente distinto de esta figura restringiéndola a la reiteración por los representantes legales de una voluntad ya previamente expresada por un niño, niña o adolescente con capacidad para ello, cuando el protagonista «se encuentra en imposibilidad para reiterarlo».

Salta a la vista que la resolución ministerial, fruto de la Sentencia T-544/17, excluye los supuestos que dieron lugar a esta última y que claramente la Corte quiso comprender; de ahí que no resulte en exceso aventurado prever futuras reclamaciones ante la jurisdicción constitucional que culminen en una nueva orden al ministerio/legislador para que la figura del consentimiento sustituto se regule de forma que los incluya. Por supuesto, a todo ello se añade la cuestión, hasta ahora no mencionada, de la atribución de la titularidad del derecho a los enfermos terminales con intensos sufrimientos mayores de edad e incapaces (sean personas devenidas incapaces pero que no ejercieron su autonomía previamente, sean incapaces absolutos que nunca han gozado de esta posibilidad ${ }^{37}$ ): ante el planteamiento de una solicitud de euta-

los enfermos un tratamiento integral que en todo caso incluya de modo preferente los cuidados paliativos.

37 Recordemos que la situación de los enfermos adultos incapaces pero que sí dejaron declaración previa de voluntad en un documento de voluntades anticipadas sí se halla expresamente prevista en la Resolución 1215 de 2015, art. 15. 
nasia por parte del representante legal de un paciente de estas características —actualmente no prevista de modo expreso, puesto que la Sentencia T-544/17 solo ordenó regular los casos de niños, niñas y adolescentes-, la Corte se encontraría en graves dificultades para fundamentar de modo racional no considerarlos titulares de un derecho previamente atribuido a otros pacientes también incapaces sobre la base de una premisa (el derecho a no sufrir como expresión de la dignidad humana) de la que no puede predicarse consistentemente otra titularidad que no sea la universal.

Parece difícil imaginar una situación más caótica que la descrita.

Al margen de lo anterior, la sentencia debería explicar de modo más convincente que a través de meras ficciones bienintencionadas (como la de que el menor incapaz quiere «ejercer su derecho a la muerte digna» y que son sus padres los que expresan su voluntad $)^{38}$ la razón por la cual el adelantamiento de la muerte de niños, niñas y adolescentes incapaces terminales habría de ser solicitado expresamente por los padres. Si de lo que se trata es de un derecho fundamental a la evitación del sufrimiento - un sufrimiento extremo médicamente constatado- basado en la dignidad y no en una autonomía que estos incapaces absolutos no pueden ejercer, ¿¿no podría sostenerse que la decisión quedara en manos del equipo médico? Con esta observación no se pretende hacer decir a la Corte lo que no dice, ni deformar su postura (en cuya base late una muy comprensible indignación de los magistrados ante una palmaria y prolongada falta de atención médica a un incapaz absoluto, para cuyo extenuante cuidado los padres no contaron con el apoyo imprescindible) a través del fácil recurso de presentarla como una suerte de inicio de una política de eugenesia de los incapaces ${ }^{39}$. Pero sí conviene recordar — como demuestran conocidos casos judicializados a nivel constitucional o cuasi-constitucional en el contexto de decisiones sobre limitación del esfuerzo terapéutico- que en ocasiones son los equipos médicos los proclives a una renuncia al tratamiento tras valorarla como la opción más favorable a los intereses del paciente, y los padres quienes, por el contrario, exigen su continuación; casos que en alguna ocasión se han resuelto - a partir de la premisa de que los padres no son siempre y necesariamente los

38 Sentencia T-544/17, II.55. Este tipo de ficciones se han empleado con frecuencia por doctrina y jurisprudencia (especialmente norteamericanas) en el contexto de las decisiones sobre la continuación de tratamiento médico de incompetentes, en el que desde antiguo se han confrontado con el estándar de los mejores intereses del paciente. Sobre ello con cierta amplitud Tomás-Valiente Lanuza (1999: 178-198).

39 Acusación que ya se le ha dirigido a la Corte tras la publicación de las sentencias. A título de ejemplo véase https://bit.ly/2WUZcOw. 
mejor situados para valorar los mayores intereses del paciente- a favor de la opción de los profesionales de retirar el soporte vital ${ }^{40}$. Volviendo a lo que ahora nos interesa: si de lo que se trata es de una decisión de adelantar la muerte del incapaz enfermo terminal que sufre intensamente, como realización de su dignidad, la reserva absoluta de la decisión a los progenitores no termina de convencer.

\section{ALGUNAS REFLEXIONES}

Las críticas que se han ido formulando a lo largo de la exposición anterior deben ahora ser completadas con una serie de reflexiones de carácter más general.

1. El giro apreciable en las últimas sentencias de la Corte colombiana evidencia en primer lugar, según creo, lo problemático de la utilización del concepto de «dignidad» por la jurisdicción constitucional cuando sirve de base, como en este caso, para crear ex novo derechos fundamentales no expresamente contemplados por el constituyente, erigiéndolo en canon de constitucionalidad autónomo de normas adoptadas por el legislador democrático que se considera que los vulneran (pues como se ha dicho, aun sin disponerlo así expresamente, de la Sentencia T-544/17 se desprende la inaplicabilidad por inconstitucional de la prohibición del adelantamiento de la muerte de nińos, niñas y adolescentes en una situación terminal con graves sufrimientos, inicialmente típica de homicidio). En otro lugar hemos profundizado en la ambigüedad del concepto (especialmente patente en el discurso bioético, en el que con no poca frecuencia se emplea en sentidos diametralmente opuestos $\left.{ }^{41}\right)$, que aconseja extremar la prudencia cuando se le confieren estas radicales consecuencias en el juicio de

40 En el contexto del amplio margen de apreciación que el TEDH suele reconocer a los Estados en la regulación de problemas relacionados con el principio y final de la vida, este enfoque es considerado compatible con el CEDH en la reciente Gard and others $v$ the United Kingdom, de 27 de junio de 2017.

41 Arruego Rodríguez (2015), Tomás-Valiente Lanuza (2014a). Aunque no sea este el caso en las sentencias que nos ocupan, donde se lo hace valer como fuente directa de nuevos derechos fundamentales, en el debate bioético de los últimos años resulta patente un uso del concepto restrictivo de derechos de libertad del individuo; además de los anteriores, insiste en ello últimamente Presno Linera (2015: 376-93). 
constitucionalidad de las normas ${ }^{42}$. En este sentido, una cosa es servirse de la consagración normativa de la dignidad de la persona (en íntima conexión con la integridad moral y la prohibición de tratos inhumanos y degradantes) como base desde la que argumentar un deber estatal positivo, jurídicamente exigible a los servicios de salud, de evitar o cuando menos aliviar el sufrimiento de los ciudadanos enfermos (al menos cuando es de tal intensidad que los reduce a seres dolientes), incluida en su caso, cuando no exista otra posibilidad para paliar síntomas refractarios, la sedación ${ }^{43}$; y otra muy distinta construir sobre ella un derecho fundamental de las personas incapaces ejercitado por sus representantes - a obtener un adelantamiento activo de la muerte que vulnera una prohibición penal previamente existente y que de facto viene a derogarse.

2. Un derecho construido sobre la autonomía individual como el sentado por la Sentencia C-239/97 excluye lógicamente a los que no reúnen las condiciones (por inmadurez psicológica o por incapacidad absoluta) para ejercerla; solo en casos de incapacidad sobrevenida en que la persona dejó previamente expresada su voluntad puede apreciarse un ejercicio de autonomía del enfermo amparable en aquel. El debate sobre la legalización del suicidio y la eutanasia, tal y como se

42 En esta línea, entre otros, Bastida Freijedo (2004: 39); más recientemente, Pascual Medrano (2015: 308, 313, 316-7).

43 Entre nosotros destaca en esta línea Gómez Tomillo (2005); en la ingente bibliografía alemana, incide en esta vertiente de la dignidad, entre otros, Birnbacher (2001: 247). La consideración del tratamiento paliativo como un verdadero derecho humano derivado de los grandes pilares mencionados en el texto se halla cada vez más extendida; sobre su reconocimiento en instrumentos y recomendaciones de organismos internacionales, con un repaso crítico a la jurisprudencia del TEDH al respecto, véasae Seatzu y Fanni (2016: 10-13). En lo que a Espańa respecta, varias comunidades autónomas cuentan, como es sobradamente conocido, con regulaciones positivas del derecho, y aunque finalmente decayera por la convocatoria electoral, al inicio de 2019 llegó a estar muy avanzada la tramitación en el Congreso de los Diputados de su regulación a nivel estatal a través de la Proposición de ley de derechos y garantías de la dignidad de la persona ante el proceso final de su vida, $B O C G$, XII Legislatura, Serie B, Núm. 66-1, 16 de diciembre de 2016.

De modo paralelo, resulta claro que la idea de dignidad entendida como prohibición de cosificación del ser humano - que se produce cuando su cuerpo se convierte en una especie de campo de batalla contra la muerte- se encuentra en la base de la prohibición del encarnizamiento terapéutico, donde opera íntimamente ligada a la prohibición de tratos degradantes. 
presenta en todas las sociedades occidentales, pivota sobre la libertad individual; presupuesta una decisión autónoma — actual o previadel enfermo (y sin ocultar la obviedad de que la apreciación de esta cualidad ha de enfrentarse a no pocas zonas grises), la cuestión clave pasa a ser la delimitación de las circunstancias objetivas de enferme$\mathrm{dad} /$ discapacidad física y sufrimiento en que consideramos adecuado, como sociedad, garantizar el acceso a la ayuda a morir. Los ordenamientos que han afrontado la legalización de estas prácticas perfilan de modos muy diferentes estas situaciones que habilitan al ejercicio del derecho; la tendencia de los últimos años, empero, es la de ir ampliando el espectro, pues aunque nunca se prescinda por completo de algún criterio delimitador, el ejercicio de autonomía individual (ya sea simultáneo o — en determinados contextos - previo a la ayuda a morir) inherente al derecho permite argumentar coherentemente la necesidad de abandonar el restrictivo criterio de la terminalidad.

Salvo posturas más radicalmente antipaternalistas, que postulan el reconocimiento del derecho a obtener ayuda a morir sea cual sea la situación médica de quien la solicita y sin que ninguna instancia «externa» más allá del individuo afectado haya de evaluar el sufrimiento padecido, su clase (físico o psíquico) o intensidad, las argumentaciones favorables a regular la ayuda a morir suelen admitir - aunque la base sobre la que se sustente sea la autonomía - su acotación a determinadas situaciones de enfermedad y sufrimiento, aquellas en las que intersubjetivamente podemos comprender la muerte más como un bien que como un daño, y en las que como sociedad podemos entender que el apoyo asistencial, incluso el óptimo, no resulte suficiente.

Los contados sistemas jurídicos con normativa al respecto afrontan la cuestión, como se ha dicho, de modo muy diverso: la opción más restrictiva de acotar el derecho a las enfermedades en estadio terminal es la acogida por los estados de los Estados Unidos que cuentan con normativa despenalizadora, y también en este momento por la ley canadiense ${ }^{44}$; todas ellas excluyen, por tanto, las situaciones de discapacidad

44 Una opción que ha originado fuerte contestación, máxime si se tiene en cuenta que la sentencia Carter no limitaba el derecho a estas situaciones (de hecho, en el momento de escribirse estas líneas ya se han interpuesto recursos por enfermos excluidos de la configuración legal del derecho): otro ejemplo (no tan extremo como el colombiano) de los desencuentros juez constitucional-legislador en nuestra materia. 
grave crónica que abocan al paciente a una absoluta dependencia y que según su origen, pueden prolongarse durante años (pacientes con parálisis muy severas de origen diverso como ELA o distrofia muscular, seccionados medulares por accidentes, minusvalías muy graves a consecuencia de ictus, etc.). En el extremo opuesto se sitúan los Países Bajos y Bélgica, que además de abarcar los tipos de casos anteriores, poco a poco han ido ampliando el espectro (bajo el paraguas de una formulación legal laxa de la situación médica requerida) a supuestos claramente distintos en los que ni siquiera es necesaria la postración física, aunque sí un padecimiento muy intenso ${ }^{45}$.

Ello se ha reconocido en varios grupos de situaciones: 1) inicio de un proceso de pérdida de facultades cognitivas (diagnóstico de Alzheimer o demencia), donde el padecimiento psicológico muy intenso deriva de ser el enfermo - todavía competente-consciente de ello y del terrible deterioro que le aguarda; 2) situaciones de demencia acompañada de un severo sufrimiento, si previamente el enfermo dejó expresada su voluntad de que en tal caso se adelantara su muerte; 3) determinadas condiciones psiquiátricas (se ha admitido en enfermos bipolares o depresivos crónicos severos) que provocan un intensísimo sufrimiento psíquico pero que se entiende que no por ello eliminan la competencia del enfermo para decidir que no quiere seguir padeciéndolo; 4) aunque no se haya consolidado en la práctica, se debate también intensamente si el derecho debería extenderse a lo que a veces se denomina el sufrimiento existencial o cansancio vital ${ }^{46}$.

3. La búsqueda de criterios razonables que orienten la solución de los problemas suscitados respecto a las personas incapaces gravemente enfermas que padecen intensamente conforma un debate paralelo al anterior, con el que sin embargo no debe confundirse. Al incurrir en esta confusión, la Corte Constitucional colombiana presta a mi juicio un flaco servicio a las posturas partidarias de la legalización del

45 La Proposición de LO 2018 reguladora de la eutanasia, por su parte, ocupa un espectro intermedio, pues además de las situaciones de enfermedad grave e incurable con pronóstico de vida limitado, incluye las de discapacidad grave crónica (art. 5 de acuerdo con las definiciones de estos conceptos en art. 3) pero ninguna de las otras situaciones admitidas en la práctica en el Benelux, salvo quizás la segunda de las detalladas supra en el texto (véase art. 6 de la Proposición).

46 De esta ampliación de lo permitido en Países Bajos y Bélgica me he ocupado en otro lugar, al que me permito remitir al lector: Tomás-Valiente Lanuza (2014b). 
suicidio asistido y la eutanasia, pues pareciera dar la razón a quienes esgrimen una determinada variante de argumentos del tipo "pendiente resbaladiza», según los cuales una legalización de las conductas solicitadas está inevitablemente llamada a dar pie a la de las que no lo sean al no existir una base conceptual sólida para diferenciarlas ${ }^{47}$. Una fundamentación adecuada del derecho, que lo ancle en la autonomía individual, permite en cambio descartar estas objeciones.

4. Lo anterior no impide reconocer que ambos contextos (los de pacientes autónomos o competentes que solicitan el adelantamiento de su muerte -incluidos aquí los que dejaron previamente dispuesta su voluntad-y los de pacientes incompetentes en situaciones extremas sobre las que inevitablemente han de adoptarse decisiones en uno u otro sentido) presentan sin duda un aspecto común: la búsqueda de soluciones adecuadas al padecimiento intenso de un ser humano enfermo. Una búsqueda que tiene lugar en un momento de profundo cambio cultural en las sociedades occidentales, en las que - tras décadas de progreso tecnológico con sus ventajas indudables (avances muy notables en el control del dolor) y otras más cuestionables (posibilidad de sacar adelante a pacientes que habrán de sobrevivir con enormes minusvalías físicas y/o físicas) - se ha dejado de ver ningún sentido al sufrimiento sin esperanza de mejora y se asume como deseable o incluso preceptiva su evitación ${ }^{48}$. Esta percepción, que en el caso de las personas con capacidad de decidir pone el foco sobre hasta qué punto reconocer un derecho de control sobre el momento y el modo de morir (que comprendería la obtención de ayuda médica para adelantar la muerte incluso en situaciones no terminales), se convierte, respecto de las personas incompetentes, en la obligación colectiva de evitar una mala muerte y procurar la mejor de las muertes posibles en las circunstancias del paciente.

A partir de esta nueva comprensión, en la discusión sobre cómo lograr una buena muerte de los pacientes incapaces han ido cristalizando diversos criterios que habrán de entrar en juego en función de la concreta situación

47 Lo que a veces se denomina la «variante lógica» de este tipo de argumentaciones, bien representada ya en su momento, entre otros muchos, por Tröndle (1987: 39-40). Al respecto, Tomás-Valiente Lanuza (1999: 147-9).

48 Sobre la interrelación entre avance tecnológico, transformaciones culturales en la comprensión de la vida y la muerte, derechos fundamentales e intervención legislativa, véase Chueca Rodríguez (2009). 
planteada (limitación del esfuerzo terapéutico, retirada de mecanismos artificiales de soporte vital, recurso a la sedación cuando no es posible otra forma de aliviar síntomas refractarios, etc.), practicados en forma variable en cada ordenamiento jurídico como fruto de una interacción constante entre diversos factores (intervención legislativa, una lex artis médica en evolución, labor de asesoramiento de los comités de ética de los centros hospitalarios) y sobre la base de estándares de decisión (los mejores intereses del paciente, la voluntad de sus representantes legales) acogidos también de forma diversa ${ }^{49}$. En este panorama intensa y consustancialmente conflictivo, pretender deducir criterios generales de actuación directamente del texto constitucional —más allá, como se ha dicho, de la garantía de una muerte sin dolor, sobre la que sí puede defenderse un deber estatal positivo en relación al derecho a la integridad moral y la prohibición de tratos degradantes - no resulta defendible, y desde luego no permite, como en el caso colombiano, una (encubierta) declaración de inconstitucionalidad, por más que limitada a los contextos de terminalidad e intenso sufrimiento, del precepto penal que prohíbe el adelantamiento de la muerte.

\section{Bibliografía}

Aguirre Román, J., Silva Rojas, A. y Pabón Mantilla, A. P. (2015). Eutanasia, estado constitucional y democracia: la validez de los argumentos religiosos en las decisiones de la Corte Constitucional Colombiana a la luz de la propuesta de Habermas sobre el rol de la religión en la esfera pública. Opinión Jurídica, 14 (27), 53-71. Disponible en: https:// doi.org/10.29375/01208578.1999.

Arruego Rodríguez, G. (2015). El recurso al concepto de dignidad humana en la argumentación biojurídica. En R. Chueca (dir.). Dignidad humana y derecho fundamental (pp. 415-444). Madrid: Centro de Estudios Políticos y Constitucionales.

Bastida Freijedo, F. J. (2004). Teoría general de los derechos fundamentales en la Constitución Española. Madrid: Tecnos. Disponible en: https://doi.org/10.18172/redur.3856.

Birnbacher, D. (2001). Instrumentalisierung und Menschenwürde. Philosophische Anmerkungen zur Debatte um Embryonen- und Stammzellforschung. Jahrbuch der Universität Düsseldorf, 243-257.

49 En el particular supuesto de las personas sumidas en estados de inconsciencia irreversible se plantea el criterio de la retirada del soporte vital pero también, en los casos en que no exista, de la alimentación/hidratación artificial, un contexto en el que juega un importante papel, precisamente, la ausencia de intereses de experiencia (dolor, sufrimiento, bienestar, placer) por parte del paciente. 
Du Bois-Pedain, A. (2007). Is there a human right to die? En B. Brooks-Gordon, F. Ebtehaj, J. Herring, M. Johnson y M. Richards. (eds.). Death Rites and Rights. Oxford; Portland: Hart Publishing.

Cepeda-Espinosa, M. J. (2004). Judicial Activism in a Violent Context: The Origin, Role, and Impact of the Colombian Constitutional Court. Washington University Global Studies Law Review, 3, 529.

Chueca Rodríguez, R. (2015). La marginalidad jurídica de la dignidad humana. En R. Chueca (dir.). Dignidad humana y derecho fundamental (pp. 25-52). Madrid: Centro de Estudios Políticos y Constitucionales.

- (2009). El marco constitucional del final de la propia vida. Revista Española de Derecho Constitucional, 85, 99-123.

Díaz Amado, E. (2017). La despenalización de la eutanasia en Colombia: contexto, bases y críticas. Revista de Bioética y Derecho, 40, 125-140.

Dworkin, R. (1998). El dominio de la vida. Barcelona: Ariel.

Ferreres Comella, V. (2007). Justicia constitucional y democracia. Madrid: Centro de Estudios Políticos y Constitucionales.

Gimbel García, J. F. (2016). Eutanasia y suicidio asistido en Canadá. Una panorámica de la sentencia Carter v. Canadá y del consiguiente Proyecto de Ley C-14 presentado por el Gobierno canadiense. Revista de Derecho de la UNED, 19, 351-378. Disponible en: https://doi.org/10.5944/rduned.19.2016.18491.

García Pereáńez, J. A. (2016). Consideraciones del bioderecho sobre la eutanasia en Colombia. Revista Latinoamericana de Bioética, 17 (1), 200-221. Disponible en: https://doi. org/10.18359/rlbi.2637.

Gómez Tomillo, M. (2005). Tratamientos paliativos e integridad moral en el contexto de la eutanasia activa indirecta. La Ley, 4, 1342-1356.

Lozano Villegas, G. (2001). La eutanasia activa en Colombia. Algunas reflexiones sobre la jurisprudencia constitucional. Revista Derecho del Estado,11, 95.

Michlowski, S. (2009). Legalising Active voluntary euthanasia through the courts: some lessons from Colombia. Medical Law Review, 17 (2), 183-218. Disponible en: https://doi. org/10.1093/medlaw/fwp006.

Pascual Medrano, A. (2015). La dignidad humana como principio jurídico del ordenamiento constitucional español. En R. Chueca (dir.). Dignidad humana y derecho fundamental (pp. 295-333). Madrid: Centro de Estudios Políticos y Constitucionales.

Presno Linera, M. Á. (2015). Dignidad humana y libre desarrollo de la personalidad. En R. Chueca (dir.). Dignidad humana y derecho fundamental, (pp. 361-393). Madrid: Centro de Estudios Políticos y Constitucionales.

Rey Martínez, F. (2015). La ayuda médica a morir como derecho fundamental (Comentario crítico de la sentencia de la Corte Suprema de Canadá de 6 de febrero de 2015, asunto Carter v. Canadá). Diario La Ley, 8512, 1.

Ruiz Miguel, A. (2010). Autonomía individual y derecho a la propia muerte. Revista Española de Derecho Constitucional, 89, 11-43.

Slaughter, A-M. (2015). A New World Order. New Jersey: Princeton University Press.

Seatzu, F. y Fanni, S. (2016). The right to palliative care: a 'mirage' in the jurisprudence of the ECTHR and IACTHR? Cuadernos de Derecho Transnacional, 8 (1), 5. 
Tomás-Valiente Lanuza, C. (2016). Deberes positivos del Estado y Derecho penal en la jurisprudencia del Tribunal Europeo de Derechos Humanos. InDret, 3.

- (2014a). La dignidad humana y sus consecuencias normativas en la argumentación jurídica: ¿un concepto útil? Revista Española de Derecho Constitucional, 102, 167-208.

- (2014b). La despenalización del suicidio asistido y la eutanasia en Europa: cuestiones abiertas. Revista Derecho a Morir Dignamente, 67, 15-23.

- (1999). La disponibilidad de la propia vida en el Derecho penal. Madrid: Centro de Estudios Políticos y Constitucionales.

Tröndle, H. (1987). Warum ist die Sterbehilfe ein rechtliches Problem? Zeitschrift für die gesamte Strafrechtswissenschaft, 99 (1), 25-48. Disponible en: https://doi.org/10.1515/ zstw.1987.99.1.25.

Viver Pi-Sunyer, C. (2013). Los efectos vinculantes de las sentencias del Tribunal Constitucional sobre el legislador: ¿puede éste reiterar preceptos legales que previamente han sido declarados inconstitucionales? Revista Española de Derecho Constitucional, 97, 13-44. 